\title{
Quality Improvement in External Radiation Therapy Using a Departmental Incident-Reporting System and Multidisciplinary Team Efforts
}

Seiichi Ota ${ }^{1,2^{*}}$, Hajime Monzen ${ }^{2}$, lori Sumida ${ }^{3}$, Yasuo Yoshioka ${ }^{3}$, Ryoko Kado $^{4}$, Shinichi Inoue ${ }^{1}$, Kazuhiko Ogawa ${ }^{3}$ and Yasumasa Nishimura $^{2}$

${ }^{1}$ Department of Medical Technology, Osaka University Hospital, Suita, Osaka, Japan

${ }^{2}$ Department of Radiation Oncology, Kinki University Graduate School of Medicine, Osaka-sayama, Osaka, Japan

${ }^{3}$ Department of Radiation Oncology, Osaka University Graduate School of Medicine, Suita, Osaka, Japan

${ }^{4}$ Department of Nursing, Osaka University Hospital, Suita, Osaka, Japan

"Corresponding author: Seiichi Ota, Department of Medical Technology, Osaka University Hospital, 2-15 Yamadaoka, Suita, Osaka-565-0871, Japan, Tel: +81-6-6879-6882; Fax: +81-6-6879-6880; E-mail: bomcooper@yahoo.co.jp

Received date: Jul 28, 2015, Accepted date: Sep 14, 2015, Publication date: Sep 18, 2015

Copyright: @ 2015 Ota S, et al. This is an open-access article distributed under the terms of the Creative Commons Attribution License; which permits unrestricted use; distribution; and reproduction in any medium; provided the original author and source are credited.

\begin{abstract}
Purpose: Incidents in radiation therapy occur due to the complex process, non-automated procedures, and miscommunication. We performed a prospective study to reduce the incidence rate during 4 years of external radiation therapy using incident-reporting system with multidisciplinary team (MDT) efforts.

Methods: Incidents from May 2009 to April 2013 were recorded, blame-free and voluntarily. The incidents involved errors which were unintended, whether they caused patient harm or not. Cause analysis of the incidents and interventions were performed through an MDT meeting in which all staff participated, including radiation oncologists, medical physicists, nurses, and radiation technologists. Our interventions included continuous feedback and improvements with minimized unnecessary stress.

Results: In total, 49 actual incidents among 2,350 radiation therapy courses were noted during the 4 years. The actual incidents occurred most frequently during treatment planning $(74 \%, 36 / 49)$, followed by treatment delivery $(20 \%, 10 / 49)$. Of the 49 actual incidents, $59 \%, 16 \%, 12 \%, 8 \%, 2 \%, 2 \%$ incidents were caused by failure to follow procedures or policies, incomplete knowledge, miscommunication, operation errors, work environment, and incorrect supervision, respectively. The actual incident rates, based on the number of treatment courses, were $4 \%, 2 \%, 1 \%$, and $1 \%$ in the first, second, third, and fourth years, respectively. We found a significant decrease in the actual incident rate during the third and fourth years compared with the first year $(p<0.01)$.
\end{abstract}

Conclusions: The frequency of incidents during radiation therapy was reduced using a voluntary incident reporting system and the efforts of a MDT.

Keywords: Incident; Learning; Radiation therapy; Multidisciplinary team; Patient safety; Quality improvement

\section{Introduction}

Patient safety issues in radiation therapy have been highlighted. Several reports on adverse events that have impacted the health of patients have been published by public organizations [1,2]. Radiation therapy processes are complex and involve many sub-processes related to equipment and performed by different staff $[3,4]$. Thus, there are many opportunities for mistakes. Several automated technologies have been developed to prevent errors, such as treatment parameters transferred automatically from the treatment planning system (TPS) to the record-and-verify $(\mathrm{R} \& \mathrm{~V})$ system $[5,6]$. However, many tasks are non-automated, including delineation of targets and organs, input treatment parameters, and set-up and patient alignment that are subject to human error.

Learning from accumulated incident reports is an approach to improving radiation safety and quality and is used widely in reliable organizations and industries, such as the airline industry. A cause analysis of an incident and developing interventions for incidents reduces future incident frequency [7]. Additionally, non-punitive and voluntary reporting provides more effective analysis and feedback [8]. The feedback approach to prevent an incident is generally reactive and is triggered when something has already gone wrong. Near misses are $\sim 100$ times more common than a critical incident and provide more learning opportunities without harming patients $[9,10]$; thus, proactive action can be allowed.

The Clinical Risk Management Committee at Osaka University Hospital reviewed hospital incident reports to plan improvements, and the Department Of Clinical Quality Management focuses on maintaining hospital-wide quality and safety with other departments [11].

However, it is insufficient for focusing on the potential value and impact of incidents in radiation therapy due to the complexity of the process. To develop safer implementation of radiation therapy, we have attempted to reduce the incident rate in external radiation therapy prospectively using incident reports collected in a non-blaming voluntary environment together with the efforts of a multidisciplinary team (MDT) in the Department Of Radiation Therapy. 
Citation: Ota S, Monzen H, Sumida I, Yoshioka Y, Kado R, et al. (2015) Quality Improvement in External Radiation Therapy Using a Departmental Incident-Reporting System and Multidisciplinary Team Efforts. J Nucl Med Radiat Ther 6: 243. doi: $10.4172 / 2155-9619.1000243$

Page 2 of 8

\section{Materials and Methods}

\section{Setting up a new organizational structure for patient safety and an internal incident report system}

Figure 1 shows our organizational structure for patient safety and quality improvements. The Clinical Risk Management Committee reviewed all hospital incident reports, and the Department Of Quality Management, consisting of several general risk managers supported other departments in implementing safety actions and convened a monthly meeting to discuss matters about which departmental clinical risk managers had raised questions, and provided relevant information. In the Department Of Radiation Therapy, a MDT meeting for patient safety was created in April 2008. The MDT meeting involves a clinical risk manager, radiation oncologist (RO), medical physicist (MP), radiological technologist (RT), and nurse. The MDT meeting investigates the causes of incidents, when necessary, and integrates efforts to improve the quality of radiation therapy.

We also began to use internal incident reporting in May 2009 under blame-free, voluntary conditions. This internal incident reporting was an extra effort to reduce incidents prospectively. Figure 1 and Table 1 show the reporting procedure to responsible staff and the incident reporting system. First, a staff member who detects an incident notifies a chief and the clinical risk manager orally. Then, the staff member(s) who detected and/or was/were involved in an incident prepare both hospital and internal incident reports. Our internal incident reporting worksheet includes the following: phase of the incident, phase of discovery, how the incident was discovered, date of the incident, date of discovery, and occupational category involved in the incident and detection of the incident.

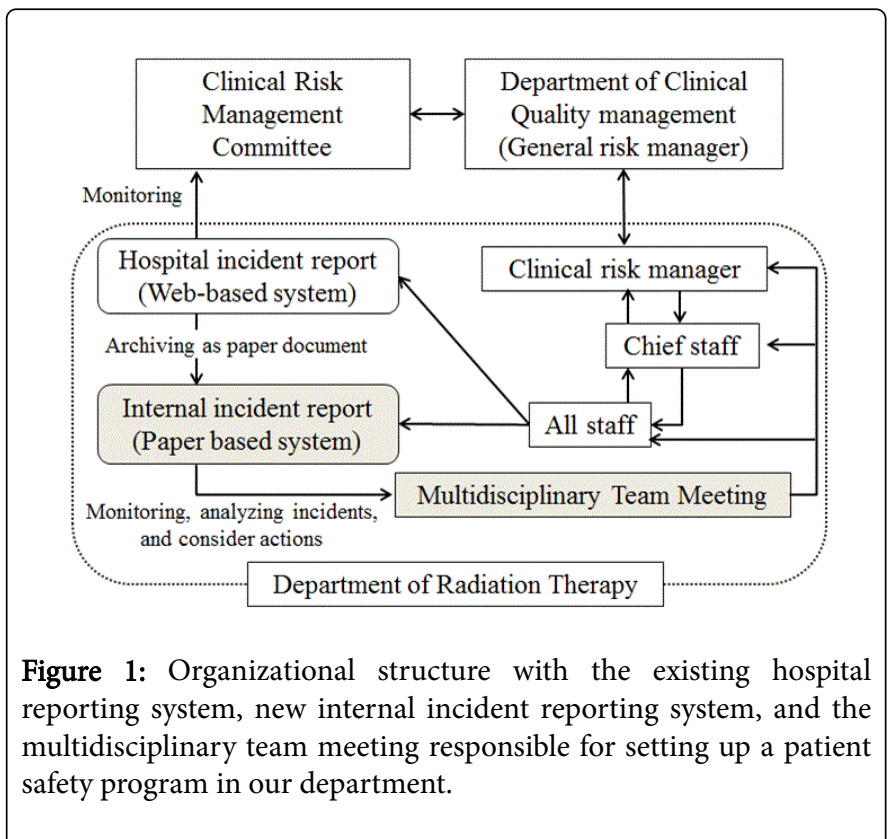

\begin{tabular}{|c|c|c|}
\hline Incident level & Examples of incidents & $\begin{array}{l}\text { Notification of responsible staff and } \\
\text { reporting }\end{array}$ \\
\hline Level 1 & $\begin{array}{l}\text { - Critical incidents had a severe impact on a patient (e.g., dose deviation from prescribed total } \\
\text { dose of }>25 \% \text { ) }\end{array}$ & \multirow{2}{*}{$\begin{array}{l}\text { - General risk managers, clinical risk managers, } \\
\text { radiation oncologist in charge, chief of staff. } \\
\text { - Immediately completed hospital incident report } \\
\text { and reported the incident to the clinical risk } \\
\text { management committee }\end{array}$} \\
\hline Level 2 & $\begin{array}{l}\text { - Major incident that had an impact on a patient (e.g., dose deviation from prescribed total dose of } \\
5-25 \% \text { that could have led to serious side effect according to the irradiated organ) }\end{array}$ & \\
\hline \multirow[t]{2}{*}{ Level 3} & $\begin{array}{l}\text { - Minor incidents that had less of an impact on a patient (e.g., }<5 \% \text { dose deviation from total } \\
\text { intended prescription dose; }<5 \mathrm{~mm} \text { geometric variation except a set-up error, no shielding of } \\
\text { normal tissue but below the tolerance dose) }\end{array}$ & \multirow{4}{*}{$\begin{array}{l}\text { - Clinical risk manager, radiation oncologist in } \\
\text { charge, chief of staff. } \\
\text { - Completed hospital incident report and } \\
\text { recorded internal incident report within } 24 \mathrm{~h}\end{array}$} \\
\hline & $\begin{array}{l}\text { - Compensable radiation incident (e.g., the final outcome, such as clinical significance, was not } \\
\text { different radiobiologically from that which was intended) }\end{array}$ & \\
\hline Level 4 & $\begin{array}{l}\text { - Near miss detected after the responsible phase but prior to starting the intended treatment plan, } \\
\text { or treatment implemented without adequate check but patient received correct treatment as a } \\
\text { result of a subsequent check }\end{array}$ & \\
\hline Level 5 & $\begin{array}{l}\text { - Non-compliance with some aspect of standard procedures but that did not directly affect } \\
\text { radiation therapy }\end{array}$ & \\
\hline Level 6 & - Errors detected and corrected as part of checking procedure during responsible phase & $\begin{array}{l}\text { - Staff involved with error } \\
\text { - Recorded internal incident report }\end{array}$ \\
\hline
\end{tabular}

Table 1: Levels of incidents, notification, and reporting.

\section{Incident levels}

Our decisions on incident level were based on Towards safer radiotherapy [2], and partially modified as following two point: (1) levels land level 2were modified according to AAPM TG-35 [12] subclassification of Class I hazards in radiation therapy (2) level 6 was an additional level: errors detected and corrected while checking standard procedure.
Levels of incidents and examples are provided in Table 1. The level of an incident was assigned by a clinical risk manager.

\section{System improvement and feedback action}

Internal incident reports were monitored by a chief RT (SO) and a chief MP. The chief in each occupational category held a non-punitive hearing regarding the incident with the staff member(s) associated 
Citation: Ota S, Monzen H, Sumida I, Yoshioka Y, Kado R, et al. (2015) Quality Improvement in External Radiation Therapy Using a Departmental Incident-Reporting System and Multidisciplinary Team Efforts. J Nucl Med Radiat Ther 6: 243. doi: $10.4172 / 2155-9619.1000243$

Page 3 of 8

with the incident to gather more information. Incidents were first analyzed and compiled by the chief RT (SO) and chief MP. Then, details of the incident were reported in the MDT meeting. All clinical staffs were invited to participate in a monthly MDT meeting, and discussed causes of incidents and making improvement plans to minimize the frequency of similar incidents when necessary. An extraordinary MDT meeting was held immediately when a level 1-3 incident was detected or a level 4-6 incident that could potentially influence a patient seriously. Feedback action was made available through mailing list and morning meetings from the chief of each occupational category. As preventative actions, pitfalls experienced were incorporated into our on-the-job trainings and educations, and were also used as resources for improving standard procedures.

\section{Incident rate calculation and statistical analysis}

Incidents were collected and analyzed for 4 years, from May 2009 to April 2013. The incident rates were calculated based on the number of treatment courses each year and tested for statistical significance using the $\chi 2$ non-parametric test with the Bonferroni correction for multiple comparisons [13].

\section{Characteristics of our department}

Our department performs approximately 600 treatment courses annually with $>900$ treatment plans and 13,500 treatment fractions delivered by two linear accelerators with an on-line megavoltage imaging device (ONCOR Impression Plus, Siemens Healthcare, Concord, CA, USA), and employs the Bright Speed Elite (GE Healthcare, Waukesha, WI, USA) as a CT-S (Computed tomography simulator). Four sets of $\mathrm{XiO}$ (Elekta, Stockholm, Sweden) are used as TPS, and LANTIS (Siemens Healthcare) is used as the R\&V system, which functions as the database for treatment parameters. iRad-RS (Infocom Corp., Tokyo, Japan) is used as the radiation therapy information system (RIS) and is linked to the hospital information system.

The RIS client computers were located along side consoles of the linear accelerator, CT-S, TPS, and R\&V systems, and in all nursing care areas and consultation rooms in our department. Our standardized procedure for radiation therapy and the responsibilities of each occupational category are summarized in Figure 2. At each phase, checklists and/or summary sheets of the TPS are used to check the procedure and the treatment information, including patient ID, patient special considerations, immobilization devices, parameters for treatment planning.

Over the 4 years, 17 ROs, 5 MPs, 27 RTs, and 8 nurses worked in our department. Normally, five ROs, two MPs, seven RTs, and five nurses worked per day in our department. Staff members with $\geq 5$ years of experience represented about half of the staff each year. New employees of each occupational category learned the standardized procedures and roles and were trained on the job by the chief and senior staff for at least 1 month. Then, their skills and knowledge were assessed by the chief in each occupational category.

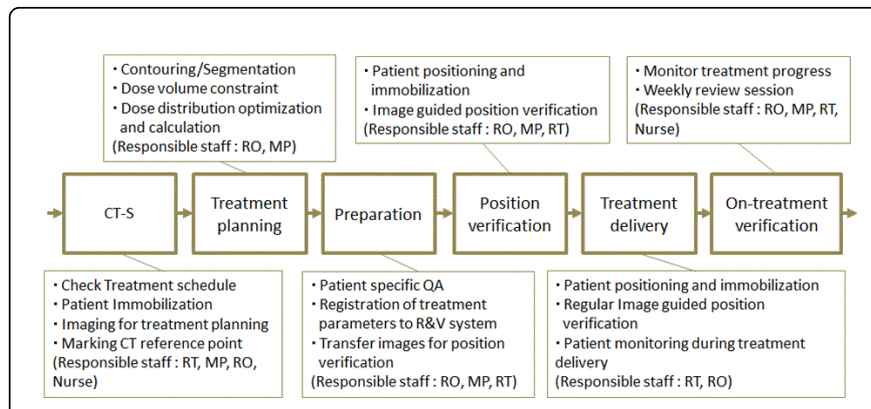

Figure 2: Workflow of radiation therapy with summary of each phases and responsible staffs in parentheses. Abbreviations: CT-S: Computed Tomography Simulation; RO: Radiation Oncologist; MP: Medical Physicist; RT: Radiological Technologist; QA: Quality Assurance; R\&V: Record And Verify.

\section{Results}

\section{Incident rate in each level per year}

In total, 435 reports were accumulated during the 4-year period. No case of level 1 or 2 was observed. There were 49 reports of level 3, 109 reports of level 4, 50 reports of level 5, and 227 reports of level 6 . The numbers of incidents and incident rates in each level during each period are shown in Table 2. The rates of level 3 were $4 \%, 2 \%, 1 \%$, and $1 \%$ in the first, second, third, and fourth years, respectively.

A significant reduction in the incident rate of level 3 was observed in the third and fourth years, compared with the first year $(\mathrm{p}<0.01)$. The incident rates of levels 4-6 decreased significantly in the second, third, and fourth years compared with those in the first year $(\mathrm{p}<0.001)$. The incident rates of each incident level according to various phases are shown in Figure 3. A gradual reduction in the level 3 incident rate was observed compared with that in the other levels. Most level 6 errors occurred in the preparation phase, and the incident rate decreased moderately over the years. The levels 3-6 incident rates during treatment planning also decreased. Number of incidents in each level also decreased spanning 4 years.

\begin{tabular}{|c|c|c|c|c|c|c|c|}
\hline \multirow[t]{2}{*}{ Period } & \multirow[t]{2}{*}{ Numbers of treatment course } & \multicolumn{6}{|c|}{ Incident level } \\
\hline & & Lv.1 & Lv.2 & Lv. $3^{*}$ & Lv. $4^{\star *}$ & Lv. $5^{\star \star}$ & Lv. $6^{* *}$ \\
\hline May 2009-April 2010 & 566 & 0 & 0 & $22(4 \%)$ & $56(10 \%)$ & $33(6 \%)$ & $132(23 \%)$ \\
\hline May 2010-April 2011 & 585 & 0 & 0 & $14(2 \%)$ & $19(3 \%)$ & $7(1 \%)$ & $58(10 \%)$ \\
\hline May 2011-April 2012 & 638 & 0 & 0 & $7(1 \%)$ & $21(3 \%)$ & $5(1 \%)$ & $25(4 \%)$ \\
\hline May 2012-April 2013 & 561 & 0 & 0 & $6(1 \%)$ & $13(2 \%)$ & $4(1 \%)$ & $12(2 \%)$ \\
\hline
\end{tabular}


Citation: Ota S, Monzen H, Sumida I, Yoshioka Y, Kado R, et al. (2015) Quality Improvement in External Radiation Therapy Using a Departmental Incident-Reporting System and Multidisciplinary Team Efforts. J Nucl Med Radiat Ther 6: 243. doi: $10.4172 / 2155-9619.1000243$

Page 4 of 8

\begin{tabular}{|l|l|l|l|l|l|l|l|}
\hline Total & 2350 & 0 & 0 & $49(2 \%)$ & $109(5 \%)$ & $50(2 \%)$ & $227(10 \%)$ \\
\hline
\end{tabular}

Table 2: Incident distribution for each classification and incident rate (\%) regarding the number of treatment courses during each period shown in parentheses. Lv., level. ${ }^{*}$ Significant incident rate reduction in the third and fourth years, compared with that in the first year ( $<<0.01$ ). ${ }^{* *}$ Significant incident rate reduction in the second, third, and fourth years, compared with that in the first year $(\mathrm{p}<0.001)$.

\section{Incident characteristics}

The characteristics of levels 3 and 4 incidents are shown in Table 3. The level 3 incidents occurred during treatment planning (74\%: 36/49), followed by treatment delivery (20\%: 10/49), preparation (2\%: $1 / 49)$, position verification $(2 \%: 1 / 49)$, and on-treatment verification $(2 \%$ : $1 / 49)$. Level 3incidents were detected in on-treatment verification (13\%: 36/49), treatment delivery (22\%: $11 / 49)$, preparation (2\%: $1 / 49)$, and other detection (2\%: 1/49).

In total, 59\% (29/49) of the level 3 incidents were failures to follow procedures and policy, $16 \%(8 / 49)$ were caused by incomplete knowledge, $12 \%(6 / 49)$ by a miscommunication, $8 \%(4 / 49)$ by manual misentry and operation, $2 \%(1 / 49)$ by work environment and $2 \%$ $(1 / 49)$ by incorrect supervision.

The ratio of level 3 incidents caused by staff members with $\geq 5$ years experience was $45 \%(22 / 49)$, and $55 \%$ (27/49) were caused by staff members with $<5$ years experience. The occupations involved in the level 3 incidents were as follows: RO (74\%: 36/49), RT (22\%: 11/49), and RO/MP (4\%:2/49). The incidents were detected by: weekly review sessions (63\%: 31/49), RT (27\%: 13/49), RO (4\%: 2/49), MP/RT (4\%: $2 / 49)$, and nurses (2\%: 1/49).

The level 4 incidents occurred during treatment planning (51\%: 55/109), followed by CT-S (21\%: 23/109), preparation (16\%: 17/109), on-treatment verification (6\%: 7/109), position verification $(6 \%$ : 6/109), and treatment delivery (1\%: 1/109).

Level 4 incidents were detected in preparation (38\%: 41/109), position verification (25\%: 27/109), treatment delivery (16\%: 17/109), on-treatment verification (15\%: 16/109), other (6\%: 7/109), and treatment planning (1\%: 1/109).

In the level 4 incidents, $45 \%$ (49/109) were due to failure to follow procedures and policy, 36\% (39/109) were caused by manual misentry and operation, $17 \%(18 / 109)$ by miscommunication, $2 \%(2 / 109)$ by skills and knowledge, and 1\% (1/109) by work environment.

The ratio of level 4 incidents caused by staff members with $\geq 5$-year experience was $61 \%(66 / 49)$, and 39\% (43/109) were caused by those with $<5$-year experience.

The occupational categories involved in level 4 were MP (36\%: 39/109), RT (31\%: 34/109), RO (30\%: 33/109), RT/MP (2\%: 2/109), and RO/MP (1\%: 1/109). Level 4 incidents were detected by: RT (68\%: 74/109), MP (17\%: 19/109), RO (7\%: 8/109), and the weekly review session (7\%: 8/109).

Our major interventions and contrivances against incidents are listed in Table 4.

\begin{tabular}{|c|c|c|c|c|c|}
\hline & \multirow[b]{2}{*}{ Parameters } & \multicolumn{2}{|l|}{ Level 3} & \multicolumn{2}{|l|}{ Level 4} \\
\hline & & Numbers & $(\%)$ & Numbers & $(\%)$ \\
\hline \multirow[t]{6}{*}{ Causes of incident } & Violation/skip procedure or policy & 29 & $59 \%$ & 49 & $45 \%$ \\
\hline & Incomplete knowledge/skill & 8 & $16 \%$ & 2 & $2 \%$ \\
\hline & Miscommunication & 6 & $12 \%$ & 18 & $17 \%$ \\
\hline & Manual misentry/operation error & 4 & $8 \%$ & 39 & $36 \%$ \\
\hline & Work environment & 1 & $2 \%$ & 1 & $1 \%$ \\
\hline & Incorrect supervision & 1 & $2 \%$ & 0 & - \\
\hline \multirow[t]{2}{*}{ Staff experiences } & $\geq 5$ years & 22 & $45 \%$ & 66 & $61 \%$ \\
\hline & $<5$ years & 27 & $55 \%$ & 43 & $39 \%$ \\
\hline \multirow[t]{5}{*}{ Caused by } & RO & 36 & $74 \%$ & 33 & $30 \%$ \\
\hline & MP & 0 & - & 39 & $36 \%$ \\
\hline & RT & 11 & $22 \%$ & 34 & $31 \%$ \\
\hline & $\mathrm{RO} / \mathrm{MP}$ & 2 & $4 \%$ & 1 & $1 \%$ \\
\hline & $\mathrm{RT} / \mathrm{MP}$ & 0 & - & 2 & $2 \%$ \\
\hline Detected by & Weekly review session & 31 & $63 \%$ & 8 & $7 \%$ \\
\hline
\end{tabular}


Citation: Ota S, Monzen H, Sumida I, Yoshioka Y, Kado R, et al. (2015) Quality Improvement in External Radiation Therapy Using a Departmental Incident-Reporting System and Multidisciplinary Team Efforts. J Nucl Med Radiat Ther 6: 243. doi: $10.4172 / 2155-9619.1000243$

Page 5 of 8

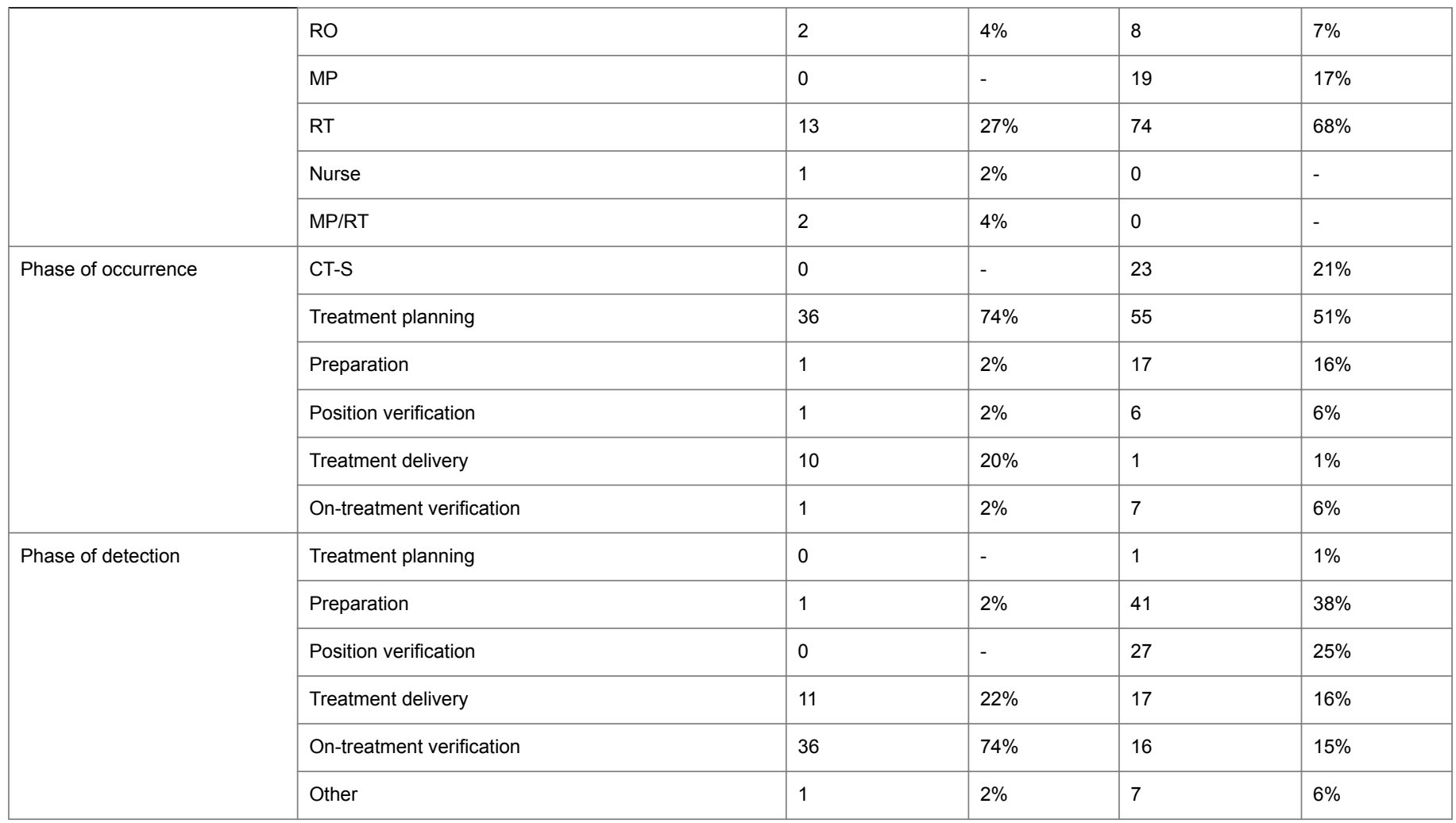

Table 3: Characteristics of level 3 and level 4 incidents. Abbreviations: RO: Radiation Oncologist; MP: Medical Physicist; RT: Radiology Technologist; CT-S: Computed Tomography Simulation. Totals may not be $100 \%$ due to rounding.

\section{General}

Increase staff training regarding to equipment operation (e.g. RIS, R\&V system, TPS, IGRT software and treatment machines, training for using of immobilization devices)

Continuous revising of checklist more comprehensibly at each phases

Sharing information in MDT morning meeting (e.g. checking tasks not yet been completed, briefing of caution points for first and complex cases)

Improving working environment (adding visual monitors in treatment room, manuals and protocols shared with a common holder on RIS, filling cabinet for handling documents such as checklist)

Inspection of transferred works at the end of operation

\section{CT-S}

Checking CT reference point coordinates and patient orientation with radiopaque makers put on front and right side of patient

ITV not created with only slow-scan technique

\section{Treatment planning}

Increasing initial plan review session by senior RO on especially complex and hypo-fraction cases

Bulletin table index for parameters not compatible with treatment machine

Logical check of parameters compatible with treatment machine in use of in-house software

Protection of final approved plan in TPS

Confirming naming policy such as plan ID and approved plans

Improving planning method (e.g. contrivance for reducing RT tasks in treatment delivery)

\section{Preparation}

RT independent checking of transferred images correct on IGRT software

Prohibiting use of shortcut keys (e.g. avoid unintended action such as field flip on R\&V system) 
Citation: Ota S, Monzen H, Sumida I, Yoshioka Y, Kado R, et al. (2015) Quality Improvement in External Radiation Therapy Using a Departmental Incident-Reporting System and Multidisciplinary Team Efforts. J Nucl Med Radiat Ther 6: 243. doi: $10.4172 / 2155-9619.1000243$

Page 6 of 8

\begin{tabular}{l} 
Position verification \\
\hline $\begin{array}{l}\text { Field shape check on R\&V system with beam's eye view after editing couch } \\
\text { Independent checks of inputted treatment couch position by senior RT }\end{array}$ \\
\hline Treatment delivery \\
\hline First treatment day attendance of MP or senior RT as checker in especially \\
Streamlining treatment delivery workflow (e.g. voice confirmation, double che \\
Patient instruction regarding to communication during treatment delivery (e.g. \\
Checking all treatment implemented as inspection of final treatment day \\
\hline On-treatment verification \\
\hline $\begin{array}{l}\text { Increase plan review sessions twice in a week } \\
\text { Continuous feedback regarding to clinical issue at weekly review session } \\
\text { Independent weekly checks of treatment schedules by senor RT and MP }\end{array}$
\end{tabular}

Table 4: Summary of major interventions and contrivances in each phase. Abbreviations: MDT: Multi-Disciplinary Team; RIS: Radiation Therapy Information System; CT-S: Computed Tomography Simulation; RO: Radiation Oncologist; TPS: Treatment Planning System; ID: Identification; RT: Radiological Technologist; IGRT: Image Guided Radiotherapy; R\&V: Record And Verify; MP: Medical Physicist.

\section{Discussion}

In this study, the rates of each incident level fell significantly over the 4 years (Table 2). Our overall incident rate for level $3(2 \%)$ was similar or slightly better than rates published by other centers [14-16]. Landrigan et al. [17] investigated efforts to improve patient safety over about 6 years in 10 hospitals and found no significant change in the overall rate of harm.

Huang et al. [16] reported a statistically significant increase in the error rate per patient per year, because patients received more complex treatments over time. Continuous risk identification with the internal incident system was a resource for ensuring patient safety. Clinical staff members often have opportunities to assess our clinical practice with many multidisciplinary interaction and interdependent tasks.

Thus, most of the interventions and contrivances taken by the MDT meeting seemed to be reasonable methods of reducing the probability of errors being repeated. Our major points of interventions and contrivances shown in Table 4 were as follows: (1) eliminating initial operator errors by sharing information in morning MDT meeting, adopting inspections at the end of operation and more comprehensible checklist, (2) enhance independent checking at initial responsible phase such as initial plan review by senior $\mathrm{RO}$, and logical plan parameters checking with in-house software, (3) increasing independent checks at subsequent phases, (4) increasing staff educations and streaming standard procedures according to experienced incidents, (5) improving work environment.

Mazur LM et.al reported that source of stress in radiation therapy were interruptions $(41.4 \%)$, time factors $(17 \%)$, technical factors (13.6\%), teamwork issues (11.6\%), patient factors $(9.0 \%)$, and environmental factors(7.4\%) [18]. Incidents made unwanted interruptions, and unnecessary interactions of staffs such as requesting time consuming works.

Especially interruption could make individual risks for omitting steps caused by disruption of normal sequence [19]. Thus, incidents might cause further potential incidents. We found high rate of level 6 incidents occurred during preparation and the treatment planning in the first year (Figure 3). Both phases have complex sub-processes and interactions of several occupational categories.

As one of our interventions checklists were revised to be more comprehensive in the MDT meetings. Gawande et al. emphasized the utility of checklists in reducing the likelihood of errors in medical services [20]. In contrast, Clark et al. indicated that introducing more comprehensive checklists caused only a short-term reduction in the number of incidents [21]. In this study, the rate of level 6 incidents in the phases of preparation and treatment planning decreased over time (Figure 3).

Our checklists were revised 11 times over 4 years. Continuous checklist reviews in the MDT meeting with incident reporting may enhance the effectiveness of checklists, and provide information on basic rules of which initial operators should be aware. Checklists at each phase were also utilized in subsequent phases as independent checks.

The rate of level 4 incidents was higher than that of level 6 incidents in the CT-S and the treatment planning phases in each year (Figure 3). This result indicates the difficulty of complete detection during a responsible phase, and the need for additional checks during subsequent phases. Morganti et al. reported the necessity for independent checks by ROs and MPs [22].

We agree regarding the need for careful independent checks; however, there has been an argument for independent checks performed mainly by ROs and MPs. In our results, $68 \%$ of level 4 incidents were detected by RTs (Table 3 ).

Our hospital adopted RT reviews of treatment plan and treatment schedules at phase of the preparation, the position verification, the treatment delivery and the on-treatment verification. In our result, not only independent checks by MPs and ROs but also checks by RTs functioned as safety barriers during many phases. 
Citation: Ota S, Monzen H, Sumida I, Yoshioka Y, Kado R, et al. (2015) Quality Improvement in External Radiation Therapy Using a Departmental Incident-Reporting System and Multidisciplinary Team Efforts. J Nucl Med Radiat Ther 6: 243. doi: $10.4172 / 2155-9619.1000243$

Page 7 of 8

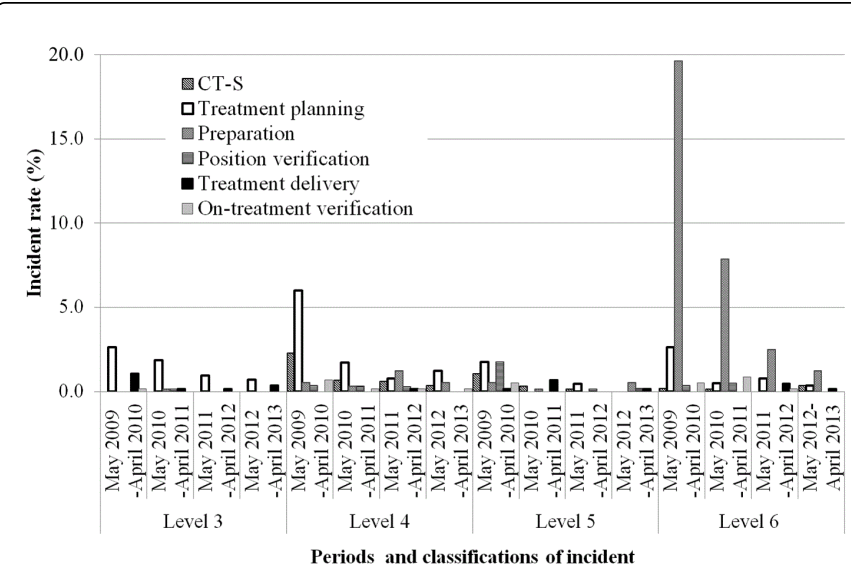

Figure 3: Periodic incident rates (\%) for each incident level (levels 1-6) during each phase. Abbreviations: CT-S: Computed Tomography Simulation.

We detected 49 of level 3 incidents during the 4 years, despite careful checks prior to the implementation of treatment delivery. The level 3 incidents detected in weekly review sessions after starting treatment (68\%:31/49) were mostly clinical issues caused by RO. Initial reviews at treatment planning by senior $\mathrm{RO}$ were increased as intervention and enhanced education (Table 4). Several reports have indicated that reliance on policies and training is the least effective approach [3,23]. Our major causes of level 3 incidents (Table 3) were failures to follow standard procedures $(59 \%)$ and incomplete knowledge (16\%). This result indicated the need for continuous education and enhanced feedback.

Numbers incidents in level 3 and level 4 at the treatment planning and the treatment delivery were 36 and 55, 10 and 1, respectively (Table 3). The treatment delivery had less safety barriers compared with treatment planning. Our MDT streamlined treatment delivery workflow such as RT double checking procedures (Table 4). We also found that $45 \%$ of level 3 incidents were caused by staff members with $\geq 5$ years experience (Table 3 ). Even less experienced staff members are needed positive confirmation to experienced staffs, and experienced staff members must not ignore their opinions, especially in treatment delivery which errors directly result in actual incidents.

Incident learning is useful for improving safety across a wide range of highly reliable organizations and industries [7,24]. In radiation oncology, cross-organizational and international voluntary reporting systems have been used to share incident information [25,26], and incident learning systems have been used successfully to improve patient safety at several institutions [15,16,21]. In our department, the MDT meeting, as a structure on the clinical side, had been empowered to improve patient safety with the internal incident learning since 2009, and the integrated clinical staff act as facilitators of quality in clinical practice presently. Thus, continuous quality improvement against incidents with the MDT meeting might have reduced the incident rate and numbers in each level during each phase (Figure 3 and Table 2).

Limitations of this study include the voluntary collection of incidents. Thus, these results may not reflect a complete overview of incidents, including near misses and errors, in our department.

\section{Conclusions}

Participation of all staff in MDT meetings seems essential to create safety culture. Incidents, including near misses and errors, can be reduced to a minimum using a non-blaming, voluntary incident reporting system and the efforts of the MDT.

\section{References}

1. World Health Organization (2008) Radiotherapy risk profile: Geneva.

2. British Institute of Radiology, Institute of Physics and Engineering in Medicine, National Patient Safety Agency, Society and College of Radiographers, The Royal College of Radiologists (2008) Towards safer radiotherapy: London.

3. American Society for Radiation Oncology (2012) Safety is No Accident: A Framework for Quality Radiation Oncology and Care: Fairfax, VA.

4. Chera BS, Jackson M, Mazur LM, Adams R, Chang S, et al. (2012) Improving quality of patient care by improving daily practice in radiation oncology. Semin Radiat Oncol 22: 77-85.

5. Fraass BA, Lash KL, Matrone GM, Volkman SK, McShan DL, et al. (1998) The impact of treatment complexity and computer-control delivery technology on treatment delivery errors. Int J Radiat Oncol Biol Phys 42: 651-659.

6. Marks LB, Light KL, Hubbs JL, Georgas DL, Jones EL, et al. (2007) The impact of advanced technologies on treatment deviations in radiation treatment delivery. Int J Radiat Oncol Biol Phys 69: 1579-1586.

7. Pronovost PJ, Goeschel CA, Olsen KL, Pham JC, Miller MR, et al. (2009) Reducing health care hazards: lessons from the commercial aviation safety team. Health Aff (Millwood) 28: w479-489.

8. Cohen MR (2000) Why error reporting systems should be voluntary. BMJ 320: 728-729.

9. Bird FE, Germain GL (1986) Practical loss control leadership, International Loss Control Institute Loganville, Georgia.

10. Barach P, Small SD (2000) Reporting and preventing medical mishaps: lessons from non-medical near miss reporting systems. BMJ 320: 759-763.

11. Nakajima K, Kurata Y, Takeda H (2005) A web-based incident reporting system and multidisciplinary collaborative projects for patient safety in a Japanese hospital. Qual Saf Health Care 14: 123-129.

12. Purdy JA, Biggs PJ, Bowers C, Dally E, Downs W, et al. (1993) Medical accelerator safety considerations: report of AAPM Radiation Therapy Committee Task Group No. 35. Med Phys 20: 1261-1275.

13. Bland JM, Altman DG (1995) Multiple significance tests: the Bonferroni method. BMJ 310: 170.

14. Yeung TK, Bortolotto K, Cosby S, Hoar M, Lederer E (2005) Quality assurance in radiotherapy: evaluation of errors and incidents recorded over a 10 year period. Radiother Oncol 74: 283-291.

15. Bissonnette JP, Medlam G (2010) Trend analysis of radiation therapy incidents over seven years. Radiother Oncol 96: 139-144.

16. Huang G, Medlam G, Lee J, Billingsley S, Bissonnette JP, et al. (2005) Error in the delivery of radiation therapy: results of a quality assurance review. Int J Radiat Oncol Biol Phys 61: 1590-1595.

17. Landrigan CP, Parry GJ, Bones CB, Hackbarth AD, Goldmann DA, et al. (2010) Temporal trends in rates of patient harm resulting from medical care. N Engl J Med 363: 2124-2134.

18. Mazur LM, Mosaly PR, Jackson M, Chang SX, Burkhardt KD, et al. (2012) Quantitative assessment of workload and stressors in clinical radiation oncology. Int J Radiat Oncol Biol Phys 83: e571-576.

19. Dismukes RK (2012) Prospective memory in workplace and everyday situations. Current Directions in Psychological Science 21:215-220.

20. Gawande A (2010) The checklist manifesto: how to get things right, Metropolitan Books, New York.

21. Clark BG, Brown RJ, Ploquin JL, Kind AL, Grimard L (2010) The management of radiation treatment error through incident learning. Radiother Oncol 95: 344-349. 
Citation: Ota S, Monzen H, Sumida I, Yoshioka Y, Kado R, et al. (2015) Quality Improvement in External Radiation Therapy Using a Departmental Incident-Reporting System and Multidisciplinary Team Efforts. J Nucl Med Radiat Ther 6: 243. doi: 10.4172/2155-9619.1000243

Page 8 of 8

22. Morganti AG, Deodato F, Zizzari S, Cilla S, Digesu' C, et al. (2008) Complexity index (COMIX) and not type of treatment predicts undetected errors in radiotherapy planning and delivery. Radiother Oncol 89: 320-329.

23. Hendee WR, Herman MG (2011) Improving patient safety in radiation oncology. Med Phys 38: 78-82.

24. Logan TJ (2008) Error prevention as developed in airlines. Int J Radiat Oncol Biol Phys 71: S178-181.
25. Holmberg O, Malone J, Rehani M, McLean D, Czarwinski R (2010) Current issues and actions in radiation protection of patients. Eur J Radiol 76: 15-19.

26. Cunningham J, Coffey M, Knöös T, Holmberg O (2010) Radiation Oncology Safety Information System (ROSIS)--profiles of participants and the first 1074 incident reports. Radiother Oncol 97: 601-607. 